\title{
Quantifying Growth Responses of Trees to Drought-a Critique of Commonly Used Resilience Indices and Recommendations for Future Studies
}

\author{
Julia Schwarz ${ }^{1}$ (D) $\cdot$ Georgios Skiadaresis ${ }^{1}$ (D) $\cdot$ Martin Kohler $^{1} \cdot$ Jörg Kunz $^{1} \cdot$ Florian Schnabel $^{2,3}$ (D) Valentina Vitali $^{4}$ (D) \\ Jürgen Bauhus ${ }^{1}$ (D)
}

Published online: 3 July 2020

(C) The Author(s) 2020

\begin{abstract}
Purpose of Review Despite the rapidly increasing use of resilience indices to analyze responses of trees and forests to disturbance events, there is so far no common framework to apply and interpret these indices for different purposes. Therefore, this review aims to identify and discuss various shortcomings and pitfalls of commonly used resilience indices and to develop recommendations for a more robust and standardized procedure with a particular emphasis on drought events.

Recent Findings Growth-based resilience indices for drought responses of trees are widely used but some important drawbacks and limitations related to their application may lead to spurious results or misinterpretation of observed patterns. The limitations include (a) the inconsistency regarding the selection and characterization of drought events and the climatic conditions in the preand post-drought period and (b) the calculation procedure of growth-based resilience indices.

Summary We discuss alternative options for metrics, which, when used in concert, can provide a more comprehensive understanding of drought responses in cases where common growth-based resilience indices are likely to fail. In addition, we propose a new analytical framework, the "line of full resilience," that integrates the three most commonly used resilience indices and show how this framework can be used for comparative drought tolerance assessments such as rankings of different tree species or treatments. The suggested approach could be used to harmonize quantifications of tree growth resilience to drought and it may thus facilitate systematic reviews and development of the urgently needed evidence base to identify suitable management options or tree species and provenances to adapt forests for changing climatic conditions.
\end{abstract}

Keywords Resilience $\cdot$ Drought tolerance $\cdot$ Tree rings $\cdot$ Extreme events $\cdot$ Forest ecosystems $\cdot$ Climate change

This article is part of the Topical Collection on Ecological Function

Electronic supplementary material The online version of this article (https://doi.org/10.1007/s40725-020-00119-2) contains supplementary material, which is available to authorized users.

Julia Schwarz

julia.schwarz@waldbau.uni-freiburg.de

1 Faculty of Environment and Natural Resources, University of Freiburg, Freiburg, Germany

2 German Centre for Integrative Biodiversity Research (iDiv) Halle-Jena-Leipzig, Leipzig, Germany

3 Systematic Botany and Functional Biodiversity, University of Leipzig, Leipzig, Germany

4 WSL Research Unit Forest Dynamics, Research Group Ecosystem-Ecology Swiss Federal Institute for Forest, Snow and Landscape Research WSL, CH-8903 Birmensdorf, Switzerland

\section{Introduction}

The last decade has provided evidence that changes regarding the world's climate are more dramatic than previously projected [1]. Droughts and associated biotic and abiotic disturbances such as fire and pest outbreaks have become one of the most important drivers of widespread forest mortality events across the globe [2, 3]. Moreover, the recent drought events represent a new drought category, so-called hotter droughts, that is, droughts coinciding with heat waves [4]. In addition, other climate extremes such as windstorms or late frost events in spring have increased in frequency, the latter negatively affecting frost-sensitive tree species in regions where increasing spring temperatures lead to premature bud break [5]. These developments make adaptation of forests to climate change one of the most pressing issues in forestry and forest conservation. The adaptation of forests to climate 
change comprises different approaches including cultivation of more drought- and heat-tolerant tree species or provenances and the development of suitable forest management strategies such as the use of mixed-species forests or shorter production cycles [6-8]. Hence, approaches that allow for an accurate and easy assessment of individual trees, species, and management scenarios regarding their tolerance during and after climatic extremes are urgently needed.

In the context of quantifying ecosystem responses to disturbance events, a number of resilience concepts have been put forward (see review by [9••]). Among the many concepts, two dominant ways to characterize resilience prevail: (a) "engineering resilience," which focuses on the transient impact of disturbance and the subsequent recovery of an ecosystem, and (b) "ecological resilience," which considers resilience as the ability of an ecosystem to withstand a shift to an alternative state in the face of disturbance [10]. Despite advances in resilience theory $[9 \bullet \bullet, 11]$, the actual quantification of resilience in forest ecosystems has remained challenging, mainly because long-term observations to determine baseline conditions are required. At the tree level, dendroecological analyses are considered particularly promising to analyze the resilience of trees to climatic extremes because tree rings provide information on growth before, during, and after an event. This is particularly relevant for applying the engineering resilience concept for several extreme events captured in one tree core or disc sample. It is worth noting, though, that this tree-level application of the resilience concept to growth is not necessarily indicative of stand or ecosystem-level resilience, which would have to consider mortality [12] and regeneration processes as well. In the field of dendroecological analyses, one concept of tree-level resilience, which describes "resistance" and "recovery" as different but complementary components of "resilience" [13, 14], has become widely used. This concept with its calculation of three resilience indices was proposed in 2011 by Lloret et al. [13], yet the calculation of the indices goes back to several older studies [15-18]. The Lloret index resistance describes a tree's capacity to absorb disturbancerelated changes in radial growth during an extreme event by comparing radial growth (e.g., ring width) during the year of disturbance to mean radial growth in a pre-disturbance period (Fig. 1 in [13]). The other indices, recovery and resilience, are calculated as average growth in the year(s) following the extreme event in relation to the growth level during the event year and in relation to the pre-drought mean of radial growth, respectively.

The popularity of the resilience indices suggested by [13] is likely attributable to their simple, yet highly efficient quantification of tree responses to disturbance. To obtain a comprehensive picture of the contexts in which studies that applied these indices were carried out, we queried all published articles citing the original study by [13] using the Web of Science and Google Scholar search engines. The result of this search (with reference month July 2019) shows a steep increase in the number of studies citing [13] for a total of 145 studies until now (Fig. S1). However, not all studies citing [13] actually calculated the indices, so the number of articles including indices of tree resilience was only 103 (Table S1). While Lloret's resilience indices may be used for the purpose of quantifying growth responses in relation to a range of different types of disturbances, the majority (82) of these studies used them to calculate tree responses to drought (Table S1) and were conducted for a total of 66 tree species. The majority of studies included comparisons of the performance among tree species $(37 \%)$, provenances $(17 \%)$, or size and age classes of trees $(17 \%)$. The remaining studies assessed the effects of geographical or site conditions $(25 \%)$, reductions in stand density (thinning) $(23 \%)$, and tree species mixtures or diversity $(17 \%)$ on tree performance in relation to drought events (note that the sum is larger than $100 \%$ because some of the studies addressed several topics, Table S1).

Hence, these indices have been used mainly for assessing drought responses of trees across a large variety of research topics and also across a large number of tree species that cover different growth characteristics and a range of forest types and climatic regions. This prompts the question to what extent one can actually compare or synthesize findings of studies that employ commonly used resilience indices including Lloret's indices.

The current lack of syntheses can be attributed to the highly inconsistent metrics for assessing drought response [19••] and there are at least three aspects contributing to this problem: first of all, there is no standardized procedure to identify drought events $[20 \bullet, 21 \bullet]$, which is the first and therefore most crucial step when studying tree responses to drought [19••, 22•]. Secondly, normalizing the different resilience indices to an undisturbed state of a system is crucial to compare the resilience indices among studies [9••]. With regard to radial tree growth, this normalization to a pre-disturbance baseline is inherently part of the calculation of resilience indices such as those proposed by Lloret et al. [13]. However, there is no standardization regarding the length of the reference period. Third, the low comparability among studies employing commonly used resilience indices is also caused by the variability of climatic conditions prior to and following individual drought events and the lack of possibilities to explicitly account for this when calculating the indices [19••].

In addition, other points of critique have been raised regarding the interpretation of results obtained when applying growth-based resilience indices to compare drought responses among tree species or treatments at different spatial scales. It has been hypothesized that there is a trade-off between resistance and recovery such that species with high resistance to drought have a low recovery and vice versa [23]. Even if such a relationship existed, it is not clear which of these components is more important to overall drought resilience: a higher 
resistance, higher recovery or higher resilience? After all, these different patterns of low resistance and high recovery vs. high resistance and low recovery represent different strategies of plants to cope with droughts in the context of the "isohydric-anisohydric framework" [24-26]. A more drought-avoiding, isohydric species would have a lower resistance during drought, whereas a drought-tolerant, anisohydric species would maintain tree ring growth at a higher level of drought stress, leading to higher resistance. However, which of these contrasting strategies is the more successful for survival depending on the intensity, duration, and timing of drought events [27]. One possible way to deal with this issue would be to interpret all indices jointly. Recently, it has been suggested that a bivariate framework could be used that jointly considers the disturbance impact (i.e., the inverse of resistance) and recovery (rate) to achieve a more comparable as-

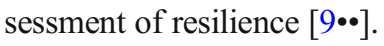

As has been shown above, despite the rapidly increasing use of resilience indices to analyze tree growth responses to drought, there is so far no common framework to apply and interpret these indices for different purposes. In this review, we aim to identify and demonstrate the shortcomings and pitfalls of commonly used resilience indices and offer recommendations for a more robust and standardized framework that integrates several of the common resilience indices. While the focus is on the application of resilience indices to drought, the points made below may be applied in parts also to other types of disturbance impacting on tree growth.

\section{Shortcomings of Commonly Used Drought Resilience Indices}

In this section, we focus on the following issues that are crucial for the quantification of resilience of tree growth in relation to drought stress:

1. An objective identification of drought

2. Considering the timing of drought in relation to speciesspecific growth dynamics

3. Consideration of climatic conditions in the pre- and postdrought period

4. Calculation of the resilience indices for different types of growth data and lengths of the reference period

\section{Objective Identification of Drought}

The identification of drought [28] is key for any type of analysis of tree growth responses to drought as the chosen approach may have a strong influence on the results. In addition, the lack of a standardized definition and quantification of drought in ecological studies hinders synthesis and process understanding [20•]. For the purpose of this study, drought can be defined as a periodic lack of water compared to normal conditions, which may be described as a meteorological drought (resulting from rainfall deficit) or soil moisture drought (below-normal soil moisture content), where the "normal" can be characterized as a percentile of the long-term mean of the variable of interest [28]. Currently, there is no standardized procedure associated with the use of growthbased indices of drought resilience.

In the studies employing Lloret's indices, drought was identified by (a) either using climatic and/or hydrological data or based on known (e.g., published) local events, (b) substantial reductions in radial tree growth, or (c) a combination of both climate and growth (Fig. S2). Only around $60 \%$ of the studies employed a selection of droughts based on climatic data, independent of information in tree growth (type a). Each of these approaches has some inherent drawbacks:

Climatic data from nearby weather stations or interpolated grid data alone may not be a precise enough indicator of the actual drought stress at a specific site as severity and duration of soil moisture deficits might not be well captured [21•]. In addition, climatic data referring to a fixed period (commonly the growing season in studies of trees and forests) will not identify all droughts with consequences for tree performance [29] because drought impacts on forests vary depending on the timing of a drought and across tree species [30-33]. For example, spring droughts but not summer droughts have been found to have a large impact on the carbon budget for Mediterranean Quercus ilex ecosystems [30].

When using growth reductions alone or in combination with climatic data to identify droughts, the response variable (growth reduction) is not independent from the predictor variable (growth resilience indices). This clearly violates the required independence of predictor variables in any statistical analysis and leads to a bias during the drought identification process as it excludes droughts that do not lead to strong growth reductions. In addition, by using only growth reductions without climatic data, one may select "false" droughts as reductions in radial growth may have other causes, such as mass seed production, defoliation through pests, late frost events that kill young foliage, or cold years [34-37]. Moreover, lagged or delayed drought responses of certain species, like Quercus sp. or Fagus sylvatica, which sometimes show growth minima only 1 year after the actual (summer) drought, could lead to temporal misalignments of the identified drought (e.g., [38-41]. In addition, this approach inevitably excludes droughts in which trees showed no growth reduction. This would lead to a misrepresentation of drought effects as only the most severe impacts are taken into account [22•]. To our knowledge, only one study quantified the effect of drought using growth-dependent vs. growth-independent methods for drought identification to estimate the uncertainty induced by the different methodologies [22•]. In this study, 
the authors compared trees in differently thinned stands and separately calculated Lloret's indices for years with low values $(<-0.84)$ of the Standardized Precipitation Evapotranspiration Index (SPEI, 42) vs. years with low SPEI values and associated basal area increment reductions of at least $10 \%$. The two methods led to different results regarding the number of identified droughts and the average growth resistance of trees in the different thinning treatments. In addition, a significant effect of the main predictor "thinning intensity" on growth resistance was only found when using the growth-dependent drought year selection, potentially overestimating thinning effects.

Hence, it is conceivable that all approaches that rely, at least in part, on tree growth responses (currently $40 \%$ of studies applying Lloret's indices) are likely leading to biased results when studying drought effects on tree growth. At this stage, an extension of the climate-based approach with the use of site-specific data, that, consistent with the suggestions of [20•], aims at characterizing droughts as period of extremes in water availability, seems to be most appropriate. As a first step, well-established drought metrics that rely on basic climatic information (temperature and precipitation) like the SPEI index are globally available or can be easily computed from other higher resolution datasets. The SPEI index might be preferred here over other indices such as the scPDSI [43] because it combines low data requirements, defined thresholds for drought intensity, and easy computation with sensitivity to global warming and a multi-scalar characteristic which permits analysis of different drought durations (but see [42]).

Such an approach alone, however, neglects the crucial importance of local soil characteristics such as the capacity to hold plant available water which can either amplify or dampen tree growth reactions to climatic droughts. In addition, it is not recommended to solely use standardized climatic indices such as SPEI for characterizing drought because standardization can lead to a misrepresentation of actual water availability and standardized values referring to different reference periods are not directly comparable [21•]. Therefore, we strongly agree with [21•] that for the identification of drought events, additional use of information on actual water stress estimated from precipitation minus potential evapotranspiration (P-PET) or preferably from the climatic water deficit, which includes data on soil moisture, should become best practice, especially as this information is increasingly available (see for example the ESA Soil Moisture CCI project or the German Drought Monitor, [44]).

\section{Considering Timing of Drought in Relation to Species- Specific Seasonal Growth Dynamics}

Growth-based resilience indices are typically calculated from annually resolved data, comparing radial growth during the drought year with (mean) growth in the previous or following year(s). In this context, it is important to distinguish drought event from drought year, where the first describes a drought that can occur over different periods of time and thus may be longer than 1 year, whereas the second occurs within one calendar year. As drought events are not necessarily synchronized with the onset and end of the growing season and because the timing and duration of wood formation differs among tree species [45], it is important to characterize drought events in relation to the developmental stage of the forming tree ring to understand species-specific growth responses to drought [46]. It has been shown that the context, timing, and duration of drought events are as important as the intensity of the drought in affecting the resistance or resilience of a species in relation to the particular extreme event $[23,47]$. This point is particularly important for comparisons of drought tolerance among tree species, which represents a common application of growth-based indices of tree resilience. For example, it has been shown that differences in resistance and resilience of radial growth to extreme drought events among three conifer species vary considerably between spring and summer droughts $[48,49]$. Hence, any comparative drought tolerance analysis of tree species based on these two indices should ideally consider several drought events capturing variation in seasonality, intensity, and duration.

Differences in vulnerability to spring or summer drought among species may also result from differences in growth dynamics, C-allocation strategies, and wood anatomy [45]. As a result, different trajectories of cumulative radial growth throughout the year appear: species with earlier onset of growth show less steep increases of cumulative growth (Species B in Fig. 1 based on Quercus robur in Fig. 2 in [50•]) while species with later onset of growth show steeper increases (Species A in Fig. 1 based on Carpinus betulus and Fagus sylvatica in Fig. 2 in [50•]). This pattern arises due to earlier achievement of maximum growth (max. cell division and cell enlargement rate) in species B compared to species A. As a consequence of earlier achievement of maximum growth, annual ring width in species B may be proportionally much less reduced during a drought leading to higher values of resistance when compared to species A with later growth peaks. This different impact on annual ring width of different species should be particularly pronounced for spring and/or early-summer droughts.

In addition, formation of earlywood in ring-porous species, such as Quercus sp., is largely dependent on remobilization of stored carbon and hence does not solely reflect the climatic conditions during that actual growth period [45] (see Fig. 2). As can be seen in Fig. 2, tree rings of similar widths can be achieved with very different proportions of cell types (years 2003 and 2004 have comparable width for oak in Fig. 2b but the dry year 2003 has a much higher proportion of latewood compared to the year 2004). Consequently, ring width may be similar, but wood density is likely to differ greatly among 


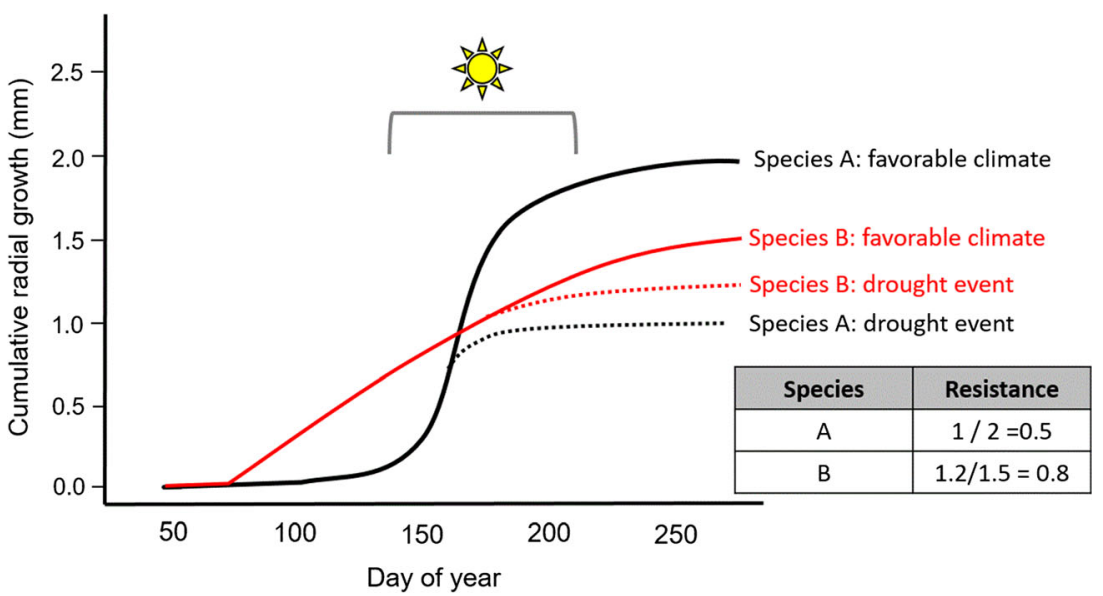

Fig. 1 Conceptual graph depicting cumulative radial growth curves of 2 hypothetical tree species with distinct growth dynamics for a normal (solid lines) vs. a dry year (dashed lines): species B is an example of a species with early growth onset and less steep radial increment while species A shows later but steeper cumulative radial growth. Growth patterns shown here are exemplary but follow in shape the cumulative radial growth depicted in Fig. 2 of [50•] with Quercus robur as an

example for species B and Fagus sylvatica and Carpinus betulus as examples for species A. Solid lines represent average growth patterns during pre-drought years with normal or favorable climatic conditions while dashed lines reflect growth dynamics during a drought when wood formation begins to cease in the middle of summer. The period of drought is indicated by the horizontal bracket. The inserted table shows resulting values of Lloret's index resistance

these years (e.g., the 2003 and 2004 ring in Quercus) (see also [51]).

Thus, in situations where tree species respond to short- and medium-term effects of droughts with production of distinctly different wood tissue [52], tree ring width or area does not appear to be a reliable basis for comparing drought responses among different tree species or drought events. After all, tree ring width is an indicator of growth performance in commonly used resilience indices, but in these situations, it would not adequately present the amount of $\mathrm{C}$ that is allocated to radial growth, especially in the extreme cases where tissue production is completely arrested. In these cases, the actual amount of wood or carbon laid down in annual rings, which can be derived from quantifying wood density (e.g., [53]), or the type and characteristics of wood cells (e.g., number and size of vessels), which can be obtained from wood anatomical studies (e.g., [54]), would be a more appropriate basis for calculating these indices. Additionally, information on cambial activity
Fig. 2 Anatomical scans of a the diffuse-porous Fagus sylvatica, compared to $\mathbf{b}$ the ring-porous Quercus petraea. Scans are derived from increment cores of trees which experienced drought stress in 2003. Cores were collected close to the city of Heppenheim in southwestern Germany. Both the pre- (2002) and post-drought (2004) year rings are visible (black borders). Early wood width (EW) is highlighted by brackets adjacent to the images in all 3 years. Images produced as described by [55], following paraffin embedding process and microtome slicing

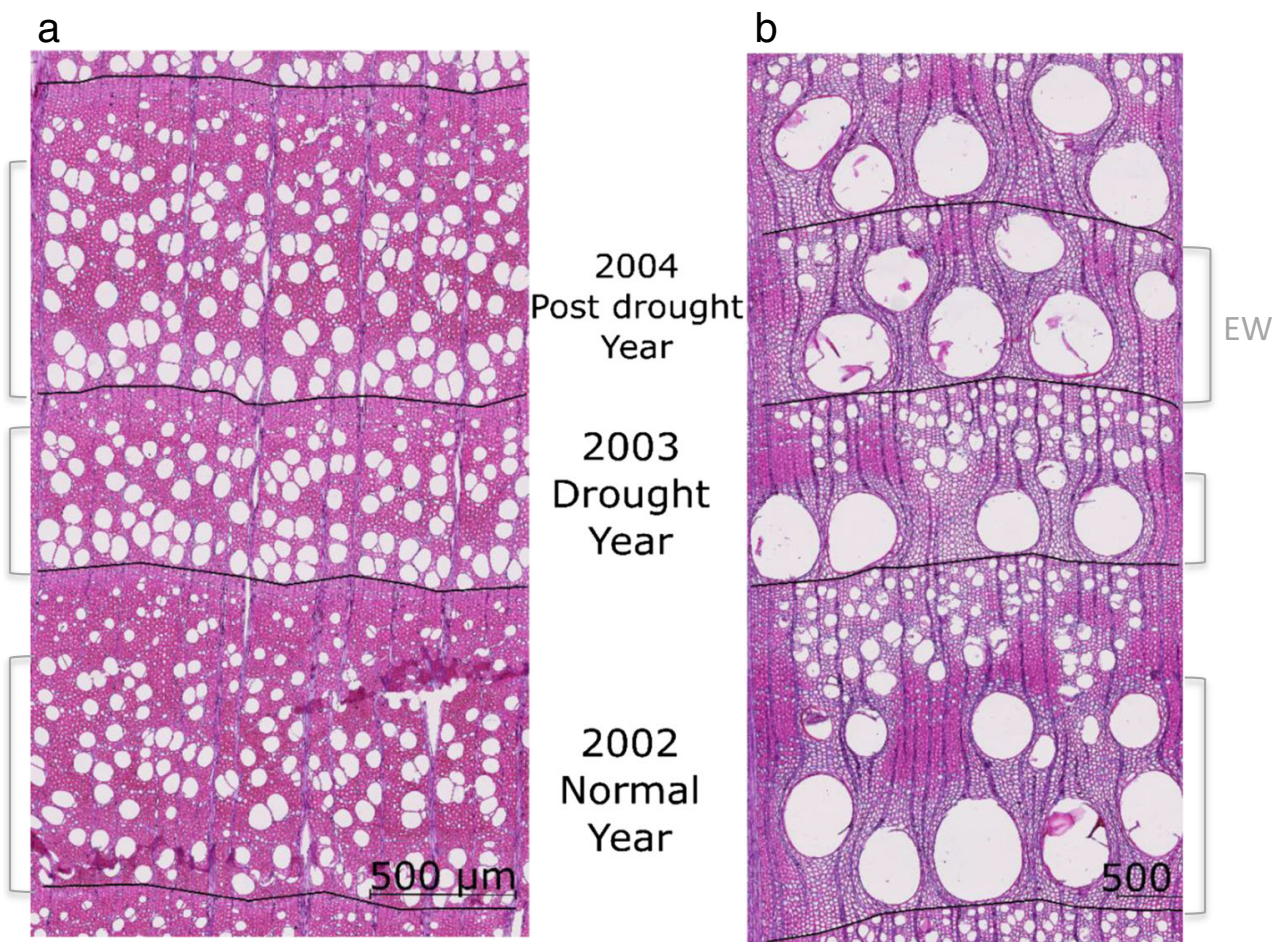


and wood formation derived from dendrometer (e.g., [50•]), cambial, or wood anatomical studies [46] in relation to the onset, timing, and duration of drought events might be necessary when comparing the drought tolerance among species or sites.

\section{Consideration of Climatic Conditions in the Pre- and Post-Drought Period}

In addition to characterizing the drought event itself in terms of its intensity, timing, and duration, one should also take into account differences in climatic conditions prevailing in the pre- and post-drought period as even moderate dry years might leave a tree more vulnerable to drought in following years [56]. Likewise, the recovery will differ largely between drought events that are followed by either ongoing water shortage or favorable conditions in the year after the drought (e.g., [22•]).

In situations of prolonged drought stress, for example, when water deficits occur during the year(s) immediately following the year with most severe drought intensity, several years may be aggregated into a single drought event. However, so far, no standardized approach for calculating growth-based resilience indices of multi-year drought events exists and this problem has been addressed in different ways. The majority of cases averaged growth of successive dry years $[13,23,57-61]$. However, a few studies used the value of the last year of the drought event [62,63], and some studies did not explain how they dealt with this issue [64-66]. Since these two approaches (average vs. last year of drought period) are likely to yield different results, we recommend that the results obtained are at least compared for the different approaches when dealing with successive dry years. In addition, when calculating resilience indices for drought events that are characterized by unfavorable climatic conditions before or after the drought event (not during the years spanning the drought period itself but several years earlier or later), the assumption of normal growth in the reference period as a baseline is obviously violated. To our knowledge, this issue has not been addressed explicitly by any of the studies calculating Lloret's indices. We propose alternative approaches dealing with this issue and the issue of multi-year droughts further below.

\section{Calculation of the Resilience Indices for Different Types of Growth Data and Lengths of the Reference Period}

The actual calculation of resilience indices depends on (1) the type of growth data used as input and (2) the number of years included in the reference period. Our literature review shows that the majority of studies (ca. 70\%) used either raw ring widths or basal area increment (BAI) to calculate the Lloret indices while $30 \%$ of the studies used detrended growth series
(Table S1). However, most studies lack a clear justification behind their choices and only one study actually compared results based on raw vs. detrended series [67]. In this study, a thinning effect on growth resistance during drought was found when using raw data, but this effect disappeared after detrending [67]. This example shows that the selection of data input types should be based on sound principles. Likewise, the length of reference periods used in previous studies ranged from \pm 1 to \pm 10 years (Table S1). In several studies, results for different lengths of the reference period were actually compared and it was found that results were consistent (e.g., [49, 68, 69]).

The high variability across studies regarding the type of growth variable, i.e., raw or detrended ring width series or $\mathrm{BAI}$, and lengths of reference periods used when calculating resilience indices may lead to inconsistencies and unreliable comparisons across studies. Especially in trees that are in a dynamic growth phase at the time of a drought event, such as juvenile or recently released trees, results are likely sensitive to data processing due to the presence of strong trends in growth series. To assess the influence of these choices, we re-analyzed the response to the 1976 drought of three published datasets, which represent three examples of differing growth dynamics depicted in Fig. 3: from (1) young (ca. 20 years old) Quercus robur stands referred to as "Young oaks" [70]; (2) mature even-aged Abies alba stands referred to as "Mature firs" [48, 49]; and (3) from recently (in the same year as the drought event) thinned Pinus sylvestris stands referred to as "Thinned pines" [22•]. For each dataset, the Lloret index resilience was calculated from different types of growth variables (raw ring width, basal area increment, and detrended ring width data using cubic smoothing splines at 0.65 of each series full length) and using four different lengths of reference periods (2, 3, 5, and 7 years) for assessing growth resilience after this extremely dry year (Fig. 3). Results of this reanalysis indicate a particularly high sensitivity of the resilience indices to different calculation methods in recently thinned pine trees (Fig. 3d-f). In this case, owing to a strong thinning-induced growth increase in the post-drought period, resilience values of basal area increment were twice as high as those of raw ring widths (Fig. 3d, e). In addition, for basal area increment, resilience doubled when the reference periods were increased from 2 to 7 years (Fig. 3e). Resilience values calculated based on BAI data were significantly higher than those based on raw and detrended data for all reference periods used (Fig. 3d-f). In contrast, resilience in young oak and mature fir trees were less affected by the type of growth variable and the length of reference periods. In the case of young oaks, resilience calculated using BAI or detrended data was significantly higher than if using raw data with a reference period of 7 years.

Based on our finding that trees in different phases of radial growth differ in their sensitivity to changes in the calculation 


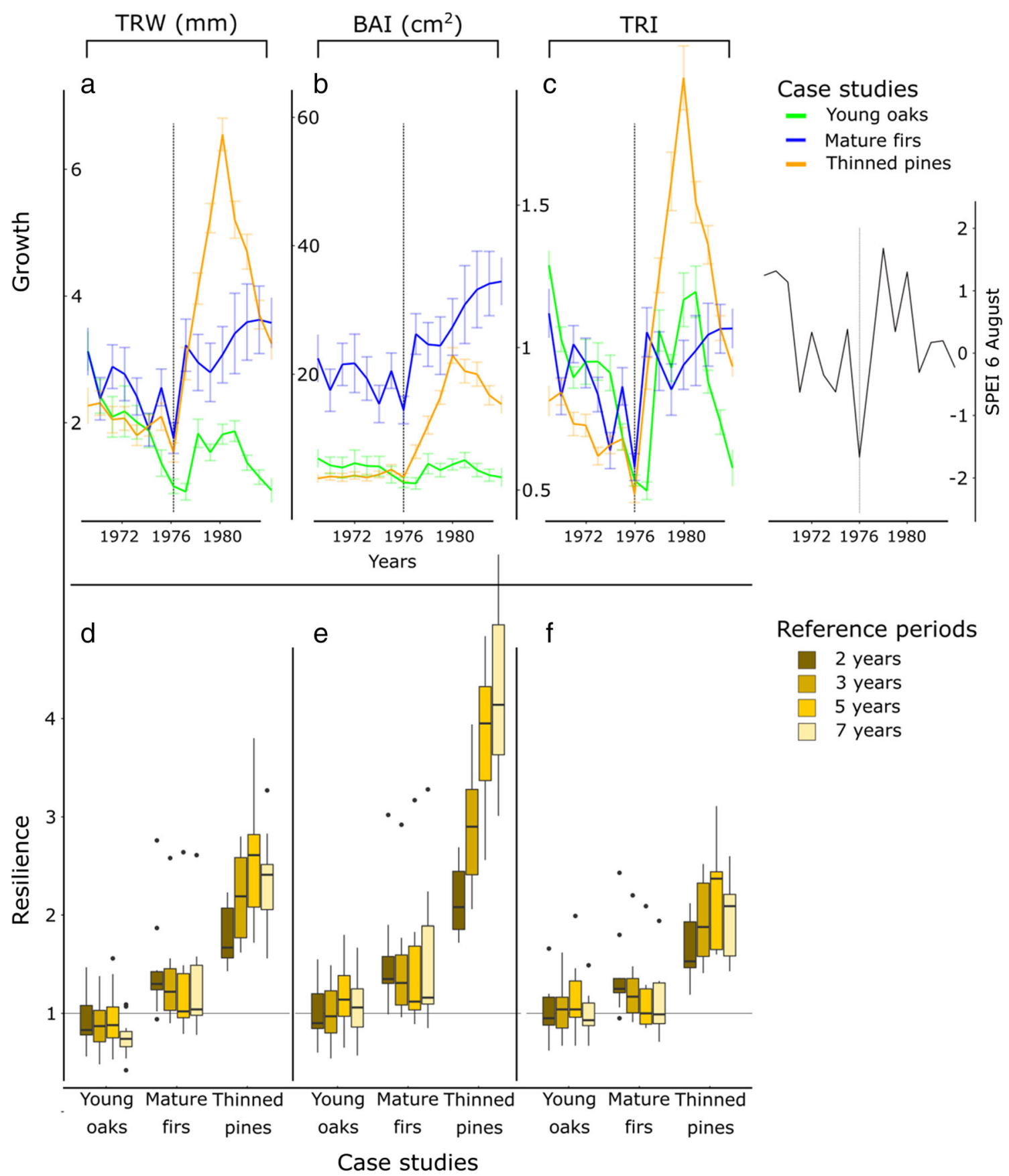

Fig. 3 Comparison of the average chronologies of three tree species (Quercus robur, Abies alba, and Pinus sylvestris) in different growth phases (young Quercus robur stands, mature Abies alba stand, and recently thinned Pinus sylvestis stand for the years around the 1976 drought event). The raw tree ring width chronology (a, left panels), basal area transformed chronologies (b, central panels), and detrended chronologies (TRI) (c, right panels) are compared. Detrending was done using cubic smoothing splines at 0.65 of each series full length. Bars in a-

procedure of the Lloret indices, we recommend to (1) evaluate the growth dynamics of trees within the untransformed; i.e., raw tree ring width, dataset, and then systematically test different transformation and detrending options for growth variables (more important if trends are present and less important c indicate the standard error of the mean. These special cases were selected for the calculation of Lloret's resilience index $(\mathbf{d}-\mathbf{f})$. Four different lengths of reference periods $(2,3,5$, and 7 years) before and after the drought year were considered for the calculations. The upper right panel shows the SPEI-6 of August (Standardized Precipitation Evapotranspiration Index) in the years around 1976 for the region of southwestern Germany $(47.75$ N, 7.75 E-49.25 N, 9.25 E, accessed from the SPEI Global Drought Monitor)

but still recommended in any type of stand); (2) test the length of the reference period in any type of stand irrespective of growth dynamics instead of using an arbitrary number of years; and (3) make an informed and evidence-based decision about the final approach and, in cases with high variation, 
report results from multiple approaches. In cases where the driver of strong growth trends is the treatment of interest, like for the "Thinned pines" in Fig. 3, it would be ideal to have a control treatment for the same species and sites, to test if changes in the calculation procedure differently affect resilience values in treated vs. untreated stands. However, if the driver is not part of the experimental treatment, removing the influenced period from the analysis might be suitable for the reasons mentioned above.

Nonetheless, the decision for or against a specific type of calculation procedure should be made as transparent as possible.

\section{Alternative Approaches to Assess Radial Growth Responses to Drought}

The shortcomings of the Lloret indices discussed above indicate that in some cases, this approach can lead to biased results and incorrect interpretations. Therefore, we discuss alternative options for three simulated cases of detrended growth data commonly observed in tree ring studies, which deviate strongly from the more theoretical examples for which the original calculation procedure of Lloret's resilience indices was designed (Fig. 1 in [13]).

In the first case (Fig. 4, Case 1), a drought event leads to a delayed growth response in the year(s) following a drought; hence, the growth minimum is observed after the actual climatic event. In the second case, growth depressions that are unrelated to drought occurred in the pre-drought reference period (Fig. 4, Case 2), which violates the assumption of normal growth in the pre-drought period. The third case illustrates situations where multiple, long-lasting, or consecutive drought events result in a prolonged recovery period (Fig. 4, Case 3). In this case, one encounters the problems that several drought years need to be summarized in a meaningful way and that the length of the post-drought reference period has to be adjusted.

We suggest that the alternative resilience indices that were introduced by $[71 \bullet \cdot]$ may be more suitable for these situations than Lloret's indices. These authors complement Lloret's resistance index with two indices accounting for the time needed to reach pre-drought growth levels (growth recovery time), subsequently called recovery period, and for the cumulative growth reduction in the drought year plus all years in the recovery period (increment loss due to drought), subsequently called total growth reduction (Fig. 2 in [71••]). Based on simulated detrended growth data, we assessed the usefulness of this alternative approach by comparing results for the three cases presented above based on Lloret's original indices with those based on the resilience indices proposed by [71••]. Further, we suggest two additional, complementary indices:
- Average growth reduction calculated as the ratio of total growth reduction divided by the length of the recovery period

- Average recovery rate as the magnitude of growth reduction in the drought year (equals 1 minus Resistance) divided by the length of the recovery period and expressed as percentage of the magnitude of growth reduction in the drought year

Hence, average growth reduction quantifies the average annual drought impact, and average recovery rate indicates how much of the growth reduction could be recovered within 1 year.

The comparison between the two methods for the first and third cases (Fig. 4, Cases 1 and 3) demonstrates the advantages of assessing both the recovery period and the total growth reduction because the length of the post-drought reference period is not pre-defined when calculating these two indices. This eliminates possible biases that can arise, if a fixed reference period is selected as is commonly done in Lloret's approach (see also previous chapter). Further, in these two examples, we obtain very low resilience values according to the Lloret index, although a complete, though prolonged recovery, which takes longer than the reference period considered for the Lloret indices, occurs. A simple application of the resilience index according to Lloret would provide the wrong impression of the capacity to recover in these cases. It is also important to note that the length of the recovery period (how fast growth returns to normal) is a key characteristic of resilient responses of trees/populations to disturbances [72] that is not captured by Lloret's approach.

Furthermore, quantifying this alternative resilience index recovery period routinely in addition to testing a set of reference periods to calculate recovery as suggested in the previous section would be one way to overcome the above-discussed lack of standardization of the reference period. This would acknowledge that the duration of recovery (if there is recovery at all) is as least as interesting as the question whether full recovery can be achieved within an arbitrarily set reference period. Thus, the additional indices suggested by $[71 \bullet \bullet]$ should be included in the analyses of growth responses to drought and especially as recent research indicates that more frequent and extreme drought events can have a prolonged effect on tree growth and function [73].

The proposed index average recovery rate, a measure of the speed of recovery, should not be assessed separately but always in combination with the other indices such as total growth reduction and the recovery period (see for example the greater recovery rate in Case 2 compared to Cases 1 and 3 in Fig. 4). The proposed index average growth reduction might be meaningful in cases where the growth reduction in the year of drought is less than the average growth reduction in the whole recovery period as for example for Case 1 in Fig. 4. 
Fig. 4 Examples of cases in which Lloret's indices are likely to provide an incomplete or misleading depiction of growth responses to drought: (1) lagged response leading to a radial growth minimum 1 year after the drought event, (2) presence of substantial growth depressions in the pre-drought reference period, and (3) multi-year or repeated drought events resulting in a prolonged recovery period. Resilience, resistance, and recovery were calculated considering 3 years as a reference period of pre- (blue horizontal lines) and post-drought (black horzontal lines) growth based on simulated detrended data setting pre-drought growth to a value of 1. Red horizontal lines represent tree ring index values in the drought year

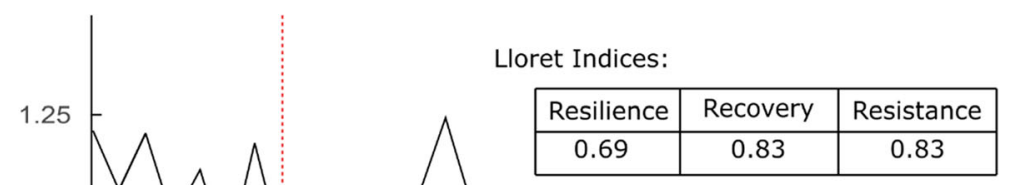

Case 1: Delayed drought response

Proposed Indices:

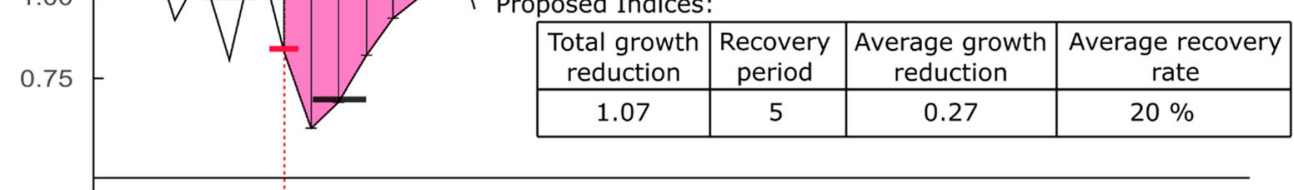

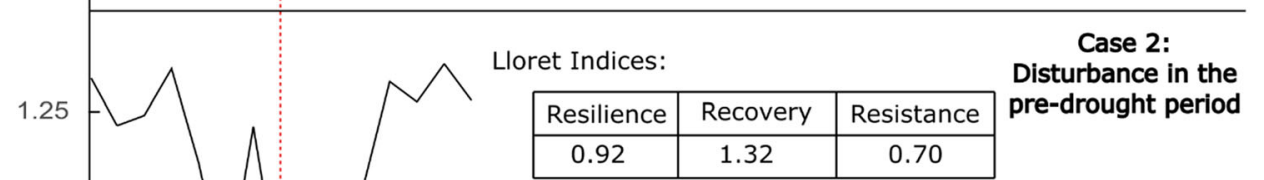

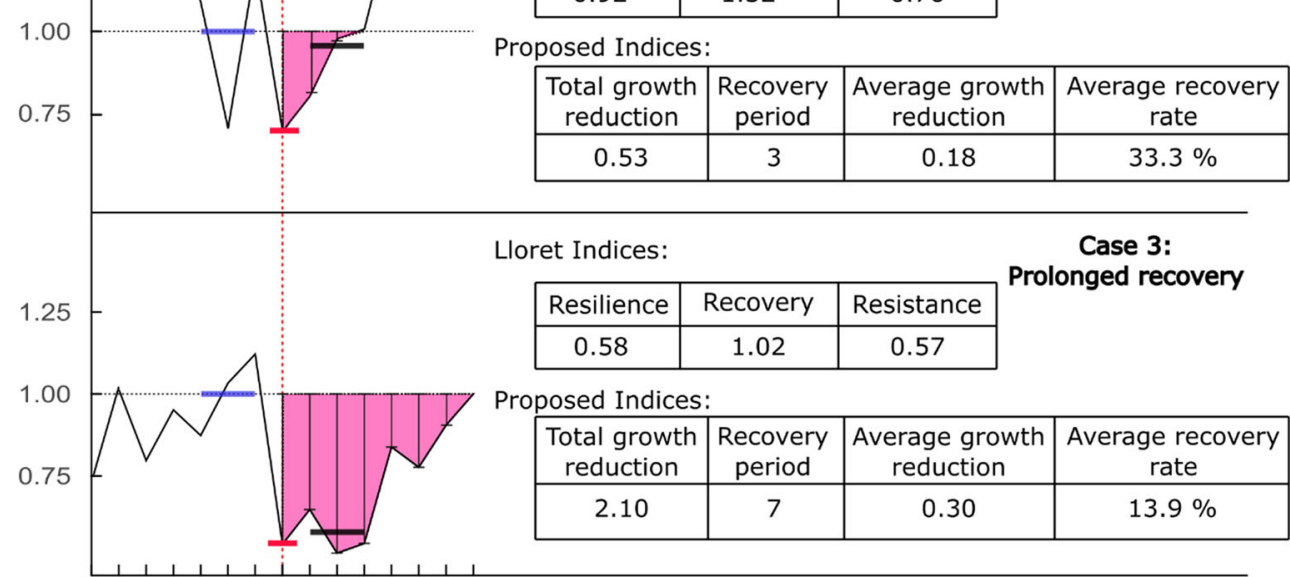

望

This metric helps to identify delayed growth responses to drought or other disturbances in the recovery period (compare Case 1 and Case 2 in Fig. 4).

When used in concert, the resilience indices proposed here can provide a more comprehensive understanding of drought responses in cases where Lloret's approach is likely to be inadequate. These resilience indices are of course interdependent but highlight different aspects of tree responses to drought. Therefore, for cases similar to the ones described above, we suggest that all four indices are assessed and reported to facilitate meaningful interpretations of drought responses.

However, these proposed approaches, like the Lloret indices, are sensitive to how pre-drought growth is defined as is demonstrated in Case 2 (Fig. 4), where both the Lloret and alternative indices might underestimate drought effects because growth in the pre-drought reference period shows significant deviations from "normal" growth. This may happen, for example, through growth suppression unrelated to drought. In this case, we suggest using a longer reference period to reduce the legacy effects on growth in the subsequent drought year or period. This example also demonstrates that neither the Lloret indices nor the alternative approaches can be effective when only very short time series of radial growth are available. One way to overcome problems with defining growth in the reference period in the case of nonnormal growth in the pre-drought period would be to use model predictions instead of actual growth values as a baseline of growth. This was done by $[74,75]$ who used models based on specific stand and climatic conditions to predict estimated annual growth before, during, and after a drought event. In one of these two studies [75], ratios between observed and estimated growth in the drought year were examined as an analogue to Lloret's resistance index, hence eliminating the need to define a reference period entirely. Clearly, the usefulness of this approach depends strongly on the quality of models to predict growth under different environmental conditions.

Future work might consider improved approaches for the definition of reference growth levels in the pre-drought and possibly post-drought period in cases where growth reaches a new equilibrium but also for cases when a drought leads to long-term growth reduction and eventually death, which may not be accounted for by detrending. Reference growth levels 
may for example be developed from separate, non-contiguous years, if they can be clearly identified as those that represent "normal growth."

As with the Lloret's indices, there is no obvious ranking of the alternative resilience indices of radial growth in order of importance. Such a ranking might be developed, if these indices can be related to an ultimate measure of drought tolerance such as the probability of tree death following droughts as recently demonstrated by [12] who found growth resilience to past droughts to be a promising proxy of tree mortality across species and regions.

\section{A New Framework for Integrated Interpretation of Tree Ring-Based Resilience Indices}

In this section, we present a novel framework that permits an integrated interpretation of the three Lloret indices. This may help to overcome the problem that there is no logical way to assign a relative weight to the different resilience indices when using them for comparing the drought tolerance of several species or treatments. The integrated framework is based on the commonly used Lloret indices because at this stage, too few studies provided values for the recommended alternative indices to allow for any robust re-analysis.

For ranking of drought tolerance among different tree species, it has been suggested that the resistance index may be the most important because highly resistant species have less need to recover compared to species with lower resistance $[23,76]$. However, as discussed above, the interpretability of the resistance index is strongly limited when comparing tree responses to drought events with different timing (e.g., summer vs. spring drought) and when comparing tree species with distinctly different seasonal growth dynamics. In addition, there may be a cost associated with having a high resistance, if growth is maintained through the use of stored carbohydrates during drought, which may lead to a depletion of non-structural C pools and possibly a less expedient recovery afterwards [40]. However, this idea is not supported by the findings of a recent global study [12] in which the drought-related mortality risk was found to be associated with lower and not higher resistance in angiosperms.

Such trade-offs between growth resistance and growth recovery were indicated by the finding of opposing trends for resistance and recovery along gradients of drought severity for Aleppo pine forests across Spain [63]. Yet, this was not confirmed in a recent meta-analysis where both functional resistance and resilience at the ecosystem scale increased along the precipitation gradient $[77 \cdot \bullet]$.

To test if there is a universal trade-off between resistance and recovery of radial growth to drought, we extracted values from all studies using the Lloret approach, which included data of resistance plus at least one other index (recovery or resilience). This allowed us to use data from 66 (out of the 82) published studies based on tree ring analyses (Table S1) leading to a total of 716 published values. A negative power function provided the best fit to these data (Spearman's $r=0.68$, residual $\mathrm{SE}=0.44)($ Fig. 5):

Recovery $=1.018 *$ Resistance ${ }^{-0.854}$

This function indicates that forest stands with stronger growth reductions during drought (lower resistance) are indeed capable of recovering faster than stands with higher resistance.

We then compared the observed relationship between resistance and recovery (Eq. 1) to a hypothetical one, which represents full resilience (value of 1 ) at any given value of resistance (red line in Fig. 5). Based on the equation by [13],

Recovery $=\frac{\text { Resilience }}{\text { Resistance }}$

one can set resilience to a constant value of 1 allowing trees to recover fully. Then one can calculate recovery at any given value of resistance as

Recovery $=\frac{1}{\text { Resistance }}$

When comparing this hypothetical relationship between resistance and recovery with the observed relationship (Fig. 5), it becomes obvious that for resistance values below 0.91 (CI between 0.75 and 1.3), recovery is not high enough to lead to full resilience of 1 . Further, the deviation from the "line of full resilience" increases with decreasing values of resistance.

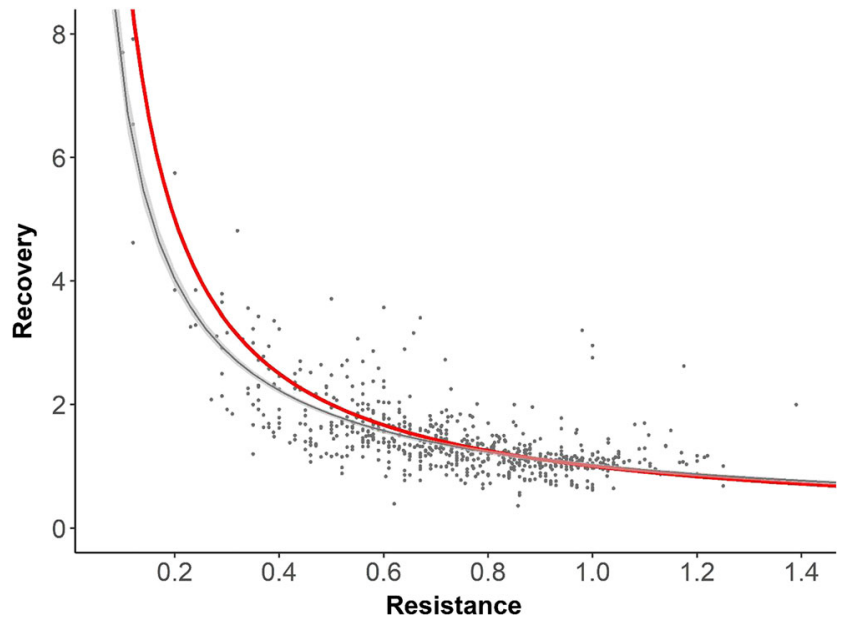

Fig. 5 Comparisons of the relationship of observed values of resistance and recovery $(N=716)$ from 66 studies (gray) to a hypothetical function, which represents full resilience at any given value of resistance (red) (see Eq. 3). The fit of the real data (gray line, see Eq. 1) is significantly better than the fit to the data using the hypothetical line of full resilience at $p<0.001 * * *$. Confidence intervals (CI) are shown as a light gray ribbon around the fit for the real data and are based on bootstrapping using 10,000 replications 
Interestingly, the majority of resistance values are located within a narrow band (roughly between 0.2 and 1.2) that are spread out over a much wider range of recovery values (roughly 1 to 4.5 ) indicating that recovery may be a more plastic trait than resistance. At a first glance, this result seems surprising when considering that tree species should operate across a large range of resistance values owing to their different water use strategies (isohydric vs. anisohydric species). However, the much larger variability of recovery compared to resistance could point to a stronger influence of extrinsic factors such as the climatic conditions in the post-drought period across studies on the first compared to the latter.

There are no values in the lower left corner (no tree had both very low resistance and low recovery) indicating a resistance threshold when growth is reduced too much. This may indicate a "physiological no-man's land," which could be assessed in future studies.

To test whether this concept captures differences between different drought events, we compared the hypothetical line of full resilience with subsets of the data shown in Fig. 5 referring to the Pan-European drought events of 1976 and 2003. These are good examples of two similarly intense drought events but with differing seasonality and climatic conditions in the pre- and postdrought period (1976 was a spring drought followed by a normal to wet year in 1977 and a very wet year in 1978; 2003 was a typical summer drought that showed prolonged water shortages until at least 2004). For the 1976 drought, the observed relationship between resistance and recovery shows a closer fit to the line of full resilience than for the 2003 drought (Fig. 6). A tree that reduced growth less than 34-57\% during the 1976 drought (i.e., had a resistance greater than $0.43-0.66$ ) could recover fully afterwards. In contrast, only trees with much smaller growth reductions of up to $19 \%$ (resistance of $0.81-1.07$ ) in the 2003 drought experienced a full recovery afterwards.

In addition, the relationship of resistance and recovery for the 1976 drought indicates an "overshooting" of recovery for resistance values higher than 0.66 (blue $\mathrm{CI}$ is entirely above red line in Fig. 6). This is most likely the result of improving growing conditions in the second half of 1976 and very favorable growing conditions in 1978, which was included in the reference period of most studies. This example shows that depending on the climatic conditions prevailing in the drought and post-drought period, the same value of resistance can lead to entirely different consequences for the recovery potential. Hence, the approach is obviously sensitive enough to capture this variation among drought events.

A logical next step would be to expand the new framework by integrating the alternative indices that were discussed in the previous section to test if/how they complement the line of full resilience. Future studies could include values of the alternative index recovery period to determine if the gray line in Fig. 5 is more likely to result from fast but incomplete recovery or from slow but complete recovery at low resistance values.

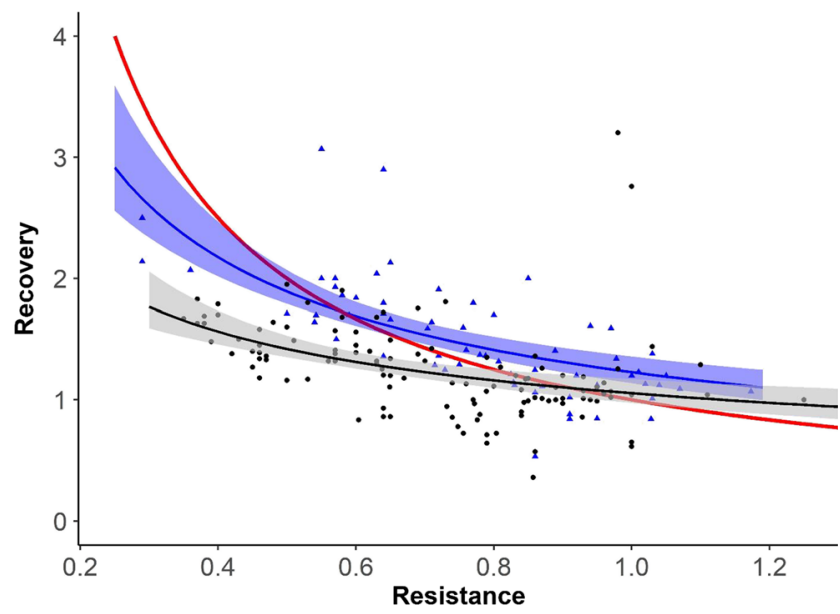

Fig. 6 Comparisons of the relationship between observed values of resistance and recovery from data of 2 drought events: the 1976 drought (blue, $N=64$ ) and the 2003 drought (gray, $N=119$ ) to the hypothetical line of full resilience (red) (see Eq. 3). Using NLS function in $\mathrm{R}$ leads to a best fit for the 1976 drought as Recovery $=$ $1.23 *$ Resistance $^{-0.62}$, with a residual SE of 0.35 and Spearman's $r=$ 0.78 , and for the 2003 drought as Recovery $=1.05 *$ Resistance $^{-0.429}$, with a residual SE of 0.35 and Spearman's $r=0.58$. Confidence intervals $(\mathrm{CI})$ are shown as a blue/gray ribbon around the fit for the real datapoints for 1976/2003 and are based on boostrapping using 10,000 replications. Data are a subset of the data extracted from the global literature based on tree ring analyses, i.e., from the 66 published studies for which both values of resistance and recovery were available (see Fig. 5 and Table S1)

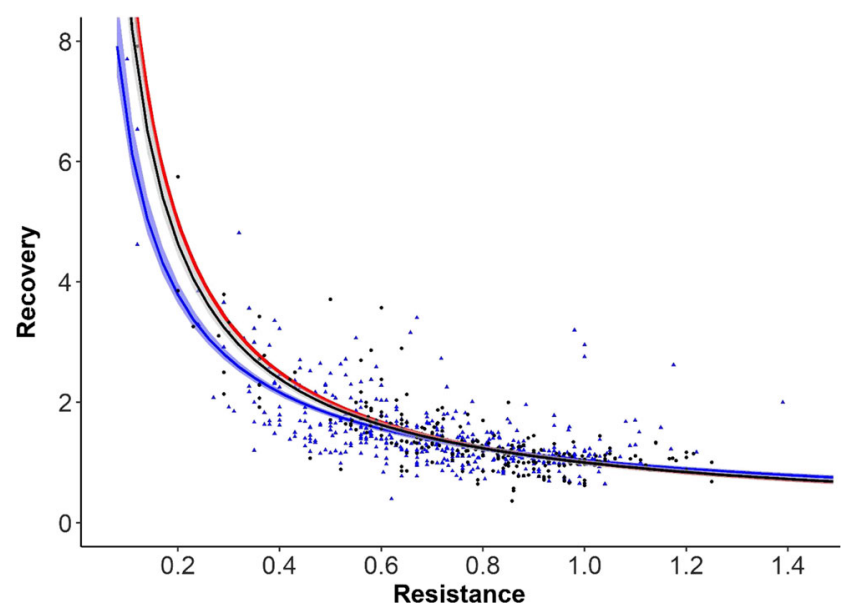

Fig. 7 Comparisons of the relationship between resistance and recovery for broadleaved ( $N=227$ trees/stands) (black) vs. coniferous species ( $N=$ 466 trees/stands) (blue) to a hypothetical one, which equates to full resilience at any given value of resistance (red) (see Eq. 3). The best fit for broadleaves is as follows: Recovery $=0.997 *$ Resistance $^{-0.95}$, with residual SE $=0.38$ and Spearman's $r=0.71$, and for conifers: Recovery $=$ $1.03 *$ Resistance $^{-0.81}$, with residual SE $=0.45$ and Spearman's $r=0.63$. Confidence intervals (CI) are shown as a blue/gray ribbon around the fit for the real datapoints for conifers/broadleaves and are based on boostrapping using 10,000 replications. Data were extracted from the global literature based on tree ring analyses, i.e., from the 66 published studies for which both values of resistance and recovery were available (see Fig. 5 and Table S1) and subset by species group 


\section{Comparing Drought Responses of Several Tree Species}

When using tree-level radial growth data, which are normally obtained from cores or discs at one stem height, one needs to consider several aspects for (a) inferring tree-level drought response, (b) scaling-up to population- or even species-level response to drought, and (c) comparing drought responses of several tree species:

Firstly, within an individual tree, extrapolation of growth data from one stem height (normally breast height, DBH) to
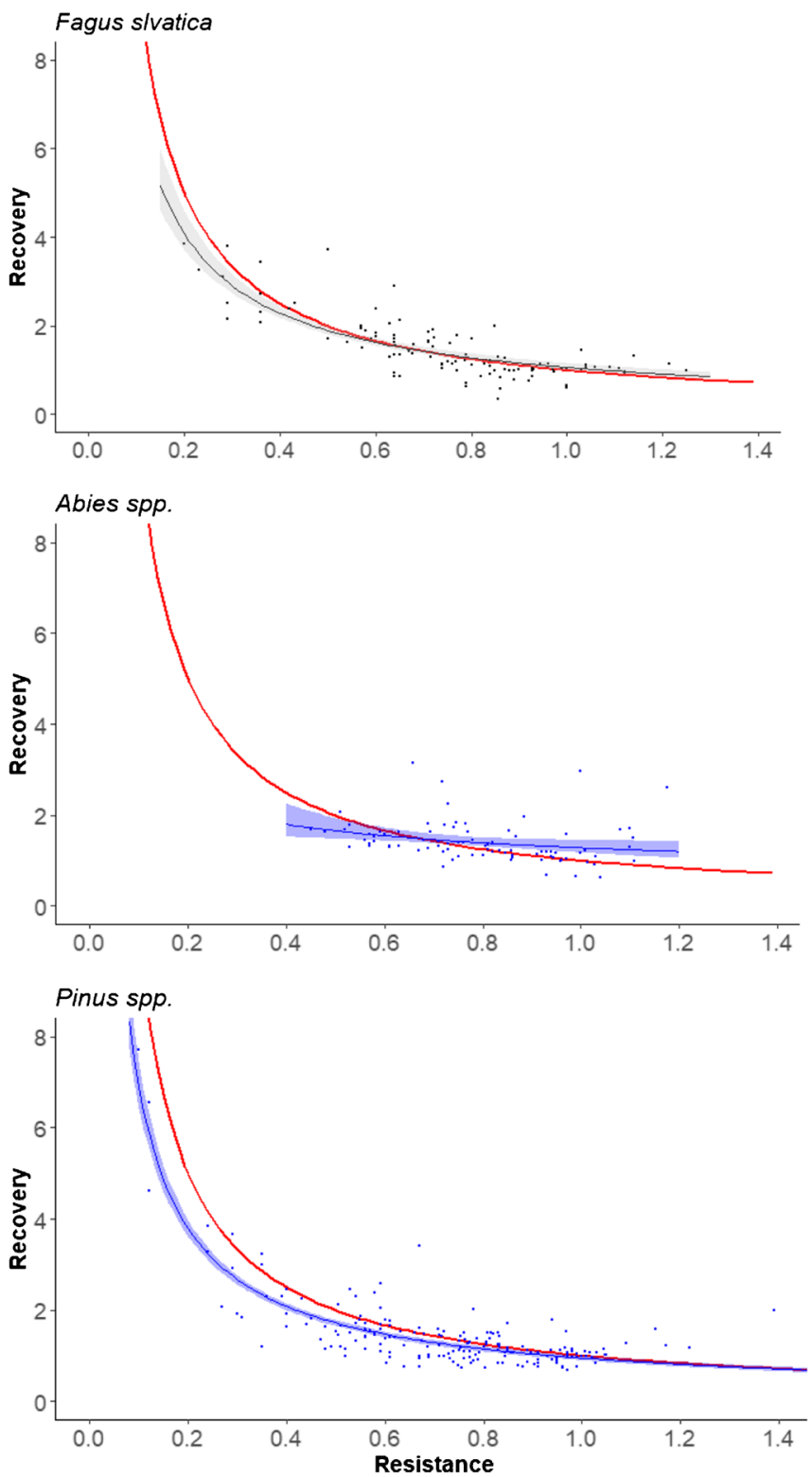

Fig. 8 Comparisons of the relationship between resistance and recovery values separately for the six most common species or genera to a hypothetical one, which equates to full resilience at any given value of resistance (red) (see Eq. 3). The coefficients, residual SE, and Spearman's $r$ values are shown in Table S2. Confidence intervals (CI) are shown as a the entire stem can be problematic, if growth responses to drought vary along the bole. This leads to biased estimates of responses of the whole tree or stem [23]. For example, basal area increments at breast height $(1.3 \mathrm{~m})$ provided good estimates of the volume growth response during drought for the whole stem in Picea abies trees, but not for recovery of growth [78]. Therefore, to improve estimates of tree-level responses to drought, future studies should use growth data from multiple stem heights.

Secondly, it is also problematic to scale-up growth responses to drought from the level of individual trees to stands,
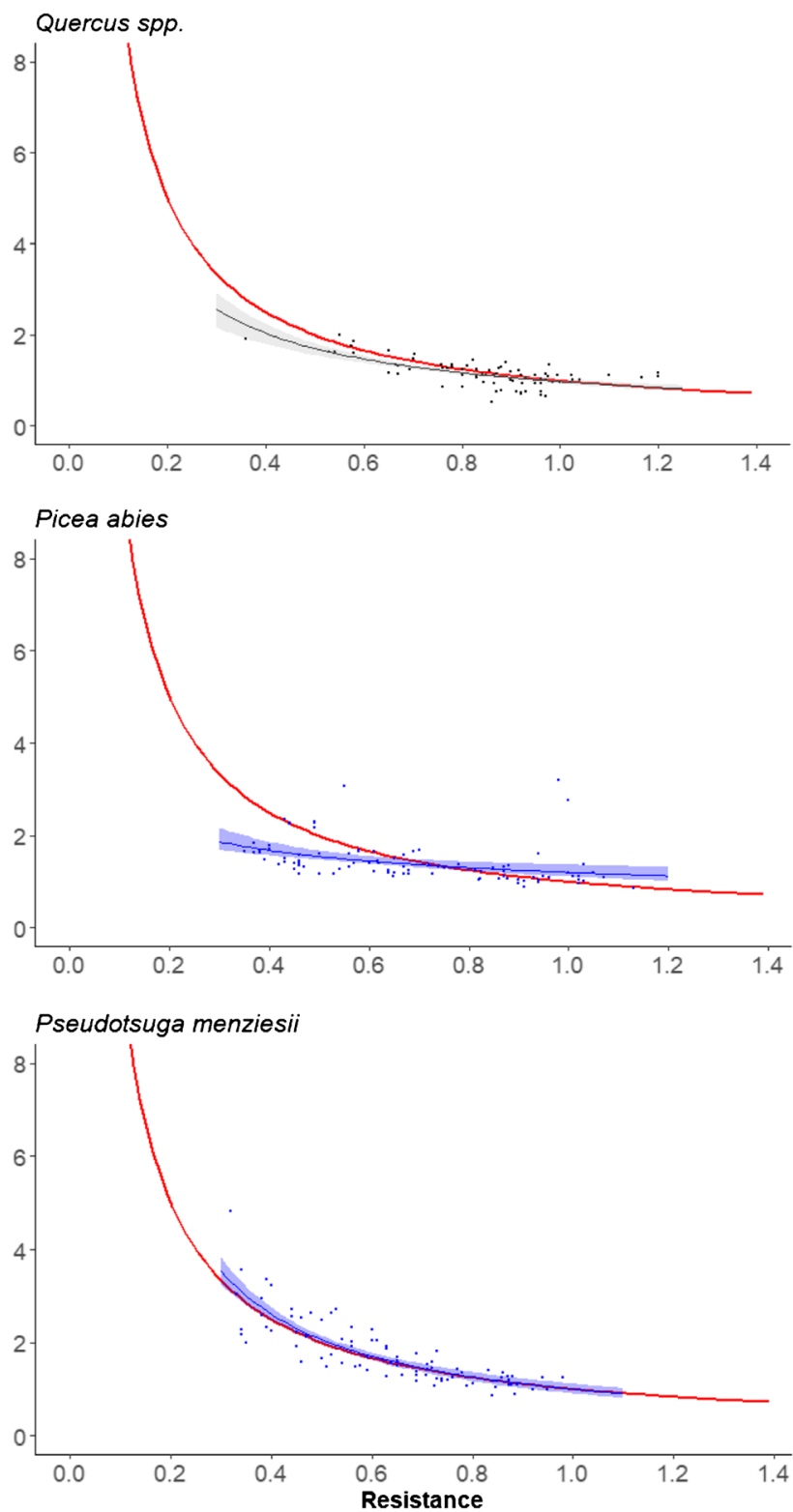

blue ribbon around the fit for the real datapoints and are based on boostrapping using 10,000 replications. Data for each genus were extracted from the global literature based on tree ring analyses, i.e., from the 66 published studies for which both values of resistance and recovery were available (see Fig. 5 and Table S1) 
populations, or even to the species level. Results of studies using Lloret's approach are representative only for that part of the population of a given species that was actually sampled. Most studies using Lloret's approach — except for [79, 80] collected growth data only from living trees, which represent the survivors of previous droughts and silvicultural selection, which would typically remove the weak and less vital trees. Hence, tree ring information has often been obtained only for the healthy and dominant or co-dominant individuals, which are least affected by stand density and supposedly carry the strongest climate signal. Yet, tree dimension and canopy status influence resistance and recovery among trees from the same population $[17,19 \bullet \cdot, 81]$. Therefore, future studies aiming at population-level growth responses should also sample dead trees [12] and trees from all vitality/size classes.

So far, comparative rankings of the drought tolerance of several tree species have been attempted only in a few studies [76, 82.]. Rankings provide an easy overview of the results of complex analyses in a condensed way, if they follow an objective and unbiased procedure and acknowledge several limitations. Certainly, it would not be very helpful to communicate the outcome of studies such as discussed above to forestry practitioners by providing them with a handful of resilience indices describing radial growth responses to drought. Therefore, we explored here whether the integrated assessment of Lloret's indices presented above could be used to support a ranking of tree species, provenances, or treatments. Subsequently, we use tree species and genus as an example for such a ranking, but they could be easily replaced by other design variables.

For this purpose, we compared regression fits for the relationship between resistance and recovery for different species or genera with the theoretical line of full resilience using the data extracted from the global literature (see Fig. 5 and Table S1). This analysis shows clear trade-offs between resistance and recovery in both conifers and broadleaves (Fig. 7), but broadleaves are much closer to the line of full resilience than conifers (ANOVA $p<0.001 * * *$ ) (Fig. 7). The deviation from the line of full resilience increases with decreasing resistance in conifers while no such trend is visible in broadleaves (Fig. 7). Using this approach for ranking purposes would lead to the conclusion that conifers should be assigned a lower drought resilience than broadleaved species.

When comparing the closeness of the observed relationship with the hypothetical line of full resilience separately for the most commonly studied species or genera in subsets of data extracted from the global literature (Fig. 8, Table S2), one can see that Pseudotsuga menziesii exhibits the closest fit followed closely by $F$. sylvatica. In contrast, $P$. abies shows the strongest deviation from the line of full resilience towards lower resistance values (Fig. 8). This indicates the highest recovery potential following droughts that lead to strong growth reductions (low resistance) in $P$. menziesii, which is in accordance with observed low mortality rates in this species following recent drought events compared to all other cooccurring species [83].

Interestingly, if we had used only the resistance index for ranking purposes, as was suggested in previous studies [23, 76], P. menziesii would have been ranked as the worstperforming species due its lowest overall means (Fig. S3).

In summary, we propose that the framework employing the line of full resilience as a reference is a promising approach to summarize growth responses of trees to drought.

\section{Conclusion}

Despite the increasing use of growth-based indices to quantify tree responses to drought, there is currently no common framework on how to apply and interpret commonly used resilience indices in a robust and meaningful way. As forests are increasingly experiencing hotter and longer drought events [84], it is necessary to develop analytical approaches that allow us to quantify responses to individual drought events (e.g., Lloret's approach), to assess the influence of successive or prolonged droughts through appropriate alternative indices (summarized in "Alternative Approaches to Assess Radial Growth Responses to Drought"), and to relate these event-focused analyses to the temporal stability of an entire tree growth series [85, 86]. One promising option for the latter would be to test whether the departure from the line of full resilience increases over time when trees experience successive droughts. In a next step, this departure may be compared across different forest ecosystems and stress levels. The suggested harmonization of quantifying resilience of tree growth to drought will facilitate systematic reviews and development of the urgently needed evidence base to identify suitable tree species and management options under climatic change. On the road towards a more meaningful and holistic evaluation of drought impacts, this review highlights potential frameworks to integrate different analytical approaches such as dendro-ecology, wood anatomy, and physiology to quantify drought responses of trees and forests.

Authors' Contributions JS and JB conceived the study. JS and GS structured the manuscript with input from all co-authors. All authors designed the study, conducted the review, and wrote individual sections of the manuscript. JK, MK, FS, and VV contributed equally.

Funding Information Open Access funding provided by Projekt DEAL. The foundations of this work were laid in several projects in which the authors were involved: a grant from the Deutsche Forschungsgemeinschaft (DFG, German Research Foundation) to JB (BA 2821/11- 1), the DRIeR project funded under the framework of the Water Research Network by the Ministry of Science, Research, and Arts of the German Federal State of Baden Wuerttemberg (AZ. 7532.21/2.1.6), and a KLIMOPASS Grant (No. 4500354096/23) provided by the Baden-Wuerttemberg Ministry of Environment, Climate and Energy to JB. FS was supported by the International Research Training Group TreeDì funded by the DFG (319936945/GRK2324). 


\section{Compliance with Ethical Standards}

Conflict of Interest Julia Schwarz, Georgios Skiadaresis, Martin Kohler, Jörg Kunz, Florian Schnabel, Valentina Vitali, and Jürgen Bauhus declare that they have no conflict of interest.

Human and Animal Rights and Informed Consent This article does not contain any studies with human or animal subjects performed by any of the authors.

Open Access This article is licensed under a Creative Commons Attribution 4.0 International License, which permits use, sharing, adaptation, distribution and reproduction in any medium or format, as long as you give appropriate credit to the original author(s) and the source, provide a link to the Creative Commons licence, and indicate if changes were made. The images or other third party material in this article are included in the article's Creative Commons licence, unless indicated otherwise in a credit line to the material. If material is not included in the article's Creative Commons licence and your intended use is not permitted by statutory regulation or exceeds the permitted use, you will need to obtain permission directly from the copyright holder. To view a copy of this licence, visit http://creativecommons.org/licenses/by/4.0/.

\section{References}

Papers of particular interest, published recently, have been highlighted as:

- Of importance

•. Of major importance

1. IPCC, editor. Climate change 2013: The physical science basis Working Group I contribution to the Fifth assessment report of the Intergovernmental Panel on Climate Change. New York: Cambridge University Press. p. 2014.

2. Allen CD, Macalady AK, Chenchouni H, Bachelet D, McDowell $\mathrm{N}$, Vennetier M, et al. A global overview of drought and heatinduced tree mortality reveals emerging climate change risks for forests. For Ecol Manag. 2010;259:660-84. https://doi.org/10. 1016/j.foreco.2009.09.001.

3. Anderegg WRL, Anderegg LDL, Kerr KL, Trugman AT. Widespread drought-induced tree mortality at dry range edges indicates that climate stress exceeds species' compensating mechanisms. Glob Chang Biol. 2019;5:170191-3802. https://doi.org/10.1111/gcb.14771.

4. Allen CD, Breshears DD, McDowell NG. On underestimation of global vulnerability to tree mortality and forest die-off from hotter drought in the Anthropocene. Ecosphere. 2015;6:1-55. https://doi. org/10.1890/ES15-00203.1.

5. Langvall O. Impact of climate change, seedling type and provenance on the risk of damage to Norway spruce (Picea abies (L.) Karst.) seedlings in Sweden due to early summer frosts. Scand J For Res. 2011;26:56-63. https://doi.org/10.1080/02827581.2011.564399.

6. Bolte A, Ammer C, Löf M, Madsen P, Nabuurs G-J, Schall P, et al. Adaptive forest management in central Europe: climate change impacts, strategies and integrative concept. Scand J For Res. 2009;24: 473-82. https://doi.org/10.1080/02827580903418224.

7. Aitken SN, Whitlock MC. Assisted gene flow to facilitate local adaptation to climate change. Annu Rev Ecol Evol Syst. 2013;44: 367-88. https://doi.org/10.1146/annurev-ecolsys-110512-135747.
8. Fares S, Mugnozza GS, Corona P, Palahí M. Sustainability: five steps for managing Europe's forests. Nature. 2015;519:407-9. https://doi.org/10.1038/519407a.

9.• Ingrisch J, Bahn M. Towards a comparable quantification of resilience. Trends Ecol Evol. 2018;33:251-9. https://doi.org/10.1016/j. tree.2018.01.013 This review about indices of ecosystem resilience to disturbance events suggests using a bivariate framework that jointly considers disturbance impact (i.e., the inverse of resistance) and recovery (rate) to achieve a more comparable assessment of resilience.

10. Holling. Engineering resilience versus ecological resilience. Washington D.C.: National Academy Press; 1996.

11. Allen CR, Angeler DG, Chaffin BC, Twidwell D, Garmestani A. Resilience reconciled. Nat Sustain. 2019;2:898-900. https://doi. org/10.1038/s41893-019-0401-4.

12. DeSoto L, Cailleret M, Sterck F, Jansen S, Kramer K, Robert EMR, et al. Low growth resilience to drought is related to future mortality risk in trees. Nat Commun. 2020;11:545. https://doi.org/10.1038/ s41467-020-14300-5.

13. Lloret F, Keeling EG, Sala A. Components of tree resilience: effects of successive low-growth episodes in old ponderosa pine forests. Oikos. 2011;120:1909-20. https://doi.org/10.1111/j.1600-0706.2011.19372.x.

14. Hodgson D, McDonald JL, Hosken DJ. What do you mean, 'resilient'? Trends Ecol Evol. 2015;30:503-6. https://doi.org/10.1016/j. tree.2015.06.010.

15. Abrams MD, Ruffner CM, Morgan TA. Tree-ring responses to drought across species and contrasting sites in the ridge and valley of Central Pennsylvania. For Sci. 1998;44:550-8.

16. Fekedulegna D, Hicks RR Jr, Colberta JJ. Influence of topographic aspect, precipitation and drought on radial growth of four major tree species in an Appalachian watershed. Forest Ecol Manag. 2003;177:409-25. https://doi.org/10.1016/S03781127(02)00446-2.

17. Martín-Benito D, Cherubini P, del Río M, Cañellas I. Growth response to climate and drought in Pinus nigra Arn. trees of different crown classes. Trees. 2008;22:363-73. https://doi.org/10.1007/ s00468-007-0191-6.

18. Kohler M, Sohn J, Nägele G, Bauhus J. Can drought tolerance of Norway spruce (Picea abies (L.) Karst.) be increased through thinning? Eur J For Res. 2010;129:1109-18. https://doi.org/10.1007/ s10342-010-0397-9.

19.• Carnwath G, Nelson C. Effects of biotic and abiotic factors on resistance versus resilience of Douglas fir to drought. PLoS One. 2017. https://doi.org/10.1371/journal.pone.0185604 The authors of this study strongly criticize the current use of growth-based indices ("highly inconsistent tree ring-based indices for quantifying drought responses").

20. Slette IJ, Post AK, Awad M, Even T, Punzalan A, Williams S, et al. How ecologists define drought, and why we should do better. Glob Chang Biol. 2019;25:3193-200. https://doi.org/10.1111/gcb.14747 This study concludes that a more detailed and consistent quantification of drought conditions would allow for more rigorous comparisons among studies.

21. Zang CS, Buras A, Esquivel-Muelbert A, Jump AS, Rigling A, Rammig A. Standardized drought indices in ecological research: why one size does not fit all. Glob Chang Biol. 2019. https://doi.org/10. 1111/gcb.14809 This paper argues that standardized climatic indices cannot be recommended as stand-alone criteria for drought severity for the purpose of identifying drought events.

22. Sohn JA, Hartig F, Kohler M, Huss J, Bauhus J. Heavy and frequent thinning promotes drought adaptation in Pinus sylvestris forests. Ecol Appl. 2016;26:2190-205. https://doi.org/10.1002/eap. 1373 This is the only study that quantifies the effect of using growth-dependent vs. growth-independent methods for drought year identification and provides an estimate of the uncertainty induced by the different methodologies. 
23. Hoffmann N, Schall P, Ammer C, Leder B, Vor T. Drought sensitivity and stem growth variation of nine alien and native tree species on a productive forest site in Germany. Agric For Meteorol. 2018;256: 431-44. https://doi.org/10.1016/j.agrformet.2018.03.008.

24. Klein T. The variability of stomatal sensitivity to leaf water potential across tree species indicates a continuum between isohydric and anisohydric behaviours. Funct Ecol. 2014;28:1313-20. https://doi. org/10.1111/1365-2435.12289.

25. Martínez-Vilalta J, Poyatos R, Aguadé D, Retana J, Mencuccini M. A new look at water transport regulation in plants. New Phytol. 2014;204:105-15. https://doi.org/10.1111/nph.12912.

26. Mirfenderesgi G, Matheny AM, Bohrer G. Hydrodynamic trait coordination and cost-benefit trade-offs throughout the isohydricanisohydric continuum in trees. Ecohydrology. 2019;12:e2041. https://doi.org/10.1002/eco.2041.

27. McDowell N, Pockman WT, Allen CD, Breshears DD, Cobb N, Kolb T, et al. Mechanisms of plant survival and mortality during drought: why do some plants survive while others succumb to drought? New Phytol. 2008;178:719-39. https://doi.org/10.1111/j. 1469-8137.2008.02436.x.

28. van Loon AF, Stahl K, Di Baldassarre G, Clark J, Rangecroft S, Wanders $\mathrm{N}$, et al. Drought in a human-modified world: reframing drought definitions, understanding, and analysis approaches. Hydrol Earth Syst Sci. 2016;20:3631-50. https://doi.org/10.5194/hess-20-3631-2016.

29. Huang M, Wang X, Keenan TF, Piao S. Drought timing influences the legacy of tree growth recovery. Glob Chang Biol. 2018;24: 3546-59. https://doi.org/10.1111/gcb.14294.

30. Allard V, Ourcival JM, Rambal S, Joffre R, Rocheteau A. Seasonal and annual variation of carbon exchange in an evergreen Mediterranean forest in southern France. Glob Chang Biol. 2008;14:714-25. https:// doi.org/10.1111/j.1365-2486.2008.01539.x.

31. Camarero J, Franquesa M, Sangüesa-Barreda G. Timing of drought triggers distinct growth responses in holm oak: implications to predict warming-induced forest defoliation and growth decline. Forests. 2015;6:1576-97. https://doi.org/10.3390/f6051576.

32. Misson L, Limousin J-M, Rodriguez R, Letts MG. Leaf physiological responses to extreme droughts in Mediterranean Quercus ilex forest. Plant Cell Environ. 2010;33:1898-910. https://doi.org/10. 1111/j.1365-3040.2010.02193.x.

33. Misson L, Degueldre D, Collin C, Rodriguez R, Rocheteau A, Ourcival J-M, et al. Phenological responses to extreme droughts in a Mediterranean forest. Glob Chang Biol. 2011;17:1036-48. https://doi.org/10.1111/j.1365-2486.2010.02348.x.

34. Piovesan G, Adams JM. Masting behaviour in beech: linking reproduction and climatic variation. Can J Bot. 2001;79:1039-47. https://doi.org/10.1139/cjb-79-9-1039.

35. Wilmking M, Hallinger M, van Bogaert R, Kyncl T, Babst F, Hahne W, et al. Continuously missing outer rings in woody plants at their distributional margins. Dendrochronologia. 2012;30:21322. https://doi.org/10.1016/j.dendro.2011.10.001.

36. Müller-Haubold H, Hertel D, Seidel D, Knutzen F, Leuschner C. Climate responses of aboveground productivity and allocation in Fagus sylvatica: a transect study in mature forests. Ecosystems. 2013;16:1498-516. https://doi.org/10.1007/s10021-013-9698-4.

37. Vacchiano G, Hacket-Pain A, Turco M, Motta R, Maringer J, Conedera M, et al. Spatial patterns and broad-scale weather cues of beech mast seeding in Europe. New Phytol. 2017;215:595-608. https://doi.org/10.1111/nph.14600.

38. Becker M, Nieminen TM, Gérémia F. Short-term variations and longterm changes in oak productivity in northeastern France. The role of climate and atmospheric CO2. Ann For Sci. 1994;51:477-92.

39. Granier A, Reichstein M, Bréda N, Janssens IA, Falge E, Ciais P, et al. Evidence for soil water control on carbon and water dynamics in European forests during the extremely dry year: 2003. Agric For Meteorol. 2007;143:123-45. https://doi.org/10.1016/j.agrformet.2006. 12.004 .
40. Galiano L, Martínez-Vilalta J, Lloret F. Carbon reserves and canopy defoliation determine the recovery of Scots pine $4 \mathrm{yr}$ after a drought episode. New Phytol. 2011;190:750-9. https://doi.org/10. 1111/j.1469-8137.2010.03628.x.

41. Meinardus C, Bräuning A. Zur Trockenstresstoleranz von Eichen und Buchen. LWF Aktuell. 2011;85:9-11.

42. Vicente-Serrano SM, Beguería S, López-Moreno JI. A multiscalar drought index sensitive to global warming: the standardized precipitation evapotranspiration index. J Clim. 2010;23:1696-718. https://doi.org/10.1175/2009JCLI2909.1.

43. Wells N, Goddard S, Hayes MJ. A self-calibrating Palmer drought severity index. J Clim. 2004;17:2335-51. https://doi.org/10.1175/ 1520-0442(2004)017<2335:ASPDSI >2.0.CO;2.

44. Zink M, Samaniego L, Kumar R, Thober S, Mai J, Schäfer D, et al. The German drought monitor. Environ Res Lett. 2016;11:74002. https://doi.org/10.1088/1748-9326/11/7/074002.

45. Michelot A, Simard S, Rathgeber C, Dufrêne E, Damesin C. Comparing the intra-annual wood formation of three European species (Fagus sylvatica, Quercus petraea and Pinus sylvestris) as related to leaf phenology and non-structural carbohydrate dynamics. Tree Physiol. 2012;32:1033-45. https://doi.org/10.1093/treephys/tps052.

46. Rathgeber CBK, Cuny HE, Fonti P. Biological basis of tree-ring formation: a crash course. Front Plant Sci. 2016;7:734. https://doi. org/10.3389/fpls.2016.00734.

47. D'Orangeville L, Maxwell J, Kneeshaw D, Pederson N, Duchesne L, Logan T, et al. Drought timing and local climate determine the sensitivity of eastern temperate forests to drought. Glob Chang Biol. 2018;24:2339-51. https://doi.org/10.1111/gcb.14096.

48. Vitali V, Buentgen U, Bauhus J. Silver fir and Douglas fir are more tolerant to extreme droughts than Norway spruce in south-western Germany. Glob Chang Biol. 2017;23:5108-19. https://doi.org/10. $1111 /$ gcb.13774.

49. Vitali V,Forrester DI, Bauhus J.Know yourneighbours: droughtresponse of Norway spruce, silver fir and douglas fir in mixed forests depends on species identity and diversity of tree neighbourhoods. Ecosystems. 2018;21:1215-29. https://doi.org/10.1007/s10021-017-0214-0.

50. van der Maaten E, Pape J, van der Maaten-Theunissen M, Scharnweber T, Smiljanic M, Cruz-García R, et al. Distinct growth phenology but similar daily stem dynamics in three co-occurring broadleaved tree species. Tree Physiol. 2018;38:1820-8. https://doi. org/10.1093/treephys/tpy042 This study provides information on how annual growth of tree species with different wood anatomies differs between wetter and drier years.

51. Barber VA, Juday GP, Finney BP. Reduced growth of Alaskan white spruce in the twentieth century from temperature-induced drought stress. Nature. 2000;405:668-73. https://doi.org/10.1038/35015049.

52. van der Werf GW, Sass-Klaassen UGW, Mohren GMJ. The impact of the 2003 summer drought on the intra-annual growth pattern of beech (Fagus sylvatica L.) and oak (Quercus robur L.) on a dry site in the Netherlands. Dendrochronologia. 2007;25:103-12. https:// doi.org/10.1016/j.dendro.2007.03.004.

53. Jacquin P, Longuetaud F, Leban J-M, Mothe F. X-ray microdensitometry of wood: a review of existing principles and devices. Dendrochronologia. 2017;42:42-50. https://doi.org/10.1016/j. dendro.2017.01.004.

54. Castagneri D, Regev L, Boaretto E, Carrer M. Xylem anatomical traits reveal different strategies of two Mediterranean oaks to cope with drought and warming. Environ Exp Bot. 2017;133:128-38. https://doi.org/10.1016/j.envexpbot.2016.10.009.

55. von Arx G, Crivellaro A, Prendin AL, Čufar K, Carrer M. Quantitative wood anatomy - practical guidelines. Front Plant Sci. 2016;7:781. https://doi.org/10.3389/fpls.2016.00781.

56. Anderegg LDL, Anderegg WRL, Berry JA. Not all droughts are created equal: translating meteorological drought into woody plant mortality. Tree Physiol. 2013;33:701-12. https://doi.org/10.1093/treephys/tpt044. 
57. Merlin M, Perot T, Perret S, Korboulewsky N, Vallet P. Effects of stand composition and tree size on resistance and resilience to drought in sessile oak and Scots pine. For Ecol Manag. 2015;339: 22-33. https://doi.org/10.1016/j.foreco.2014.11.032.

58. Keyser TL, Brown PM. Drought response of upland oak (Quercus L.) species in Appalachian hardwood forests of the southeastern USA. Ann For Sci. 2016;73:971-86. https://doi.org/10.1007/s13595-016-0575-0.

59. George J-P, Grabner M, Karanitsch-Ackerl S, Mayer K, Weissenbacher L, Schueler S. Genetic variation, phenotypic stability, and repeatability of drought response in European larch throughout 50 years in a common garden experiment. Tree Physiol. 2017;37:33-46. https://doi.org/10.1093/treephys/tpw085.

60. Serra-Maluquer X, Mencuccini M, Martinez-Vilalta J. Changes in tree resistance, recovery and resilience across three successive extreme droughts in the northeast Iberian Peninsula. Oecologia. 2018;187:343-54. https://doi.org/10.1007/s00442-018-4118-2.

61. Vanhellemont M, Sousa-Silva R, Maes SL, van den Bulcke J, Hertzog L, de Groote SRE, et al. Distinct growth responses to drought for oak and beech in temperate mixed forests. Sci Total Environ. 2019;650: 3017-26. https://doi.org/10.1016/j.scitotenv.2018.10.054.

62. Gazol A, Camarero JJ, Gomez-Aparicio L. Functional diversity enhances silver fir growth resilience to an extreme drought. J Ecol. 2016;104:1063-75. https://doi.org/10.1111/1365-2745.12575.

63. Gazol A, Ribas M, Gutiérrez E, Camarero JJ. Aleppo pine forests from across Spain show drought-induced growth decline and partial recovery. Agric For Meteorol. 2017;232:186-94. https://doi.org/10. 1016/j.agrformet.2016.08.014.

64. Moricz N, Garamszegi B, Rasztovits E, Bidlo A, Horvath A, Jagicza A, et al. Recent drought-induced vitality decline of black pine (Pinus nigra Arn.) in south-west Hungary. Is this droughtresistant species under threat by climate change? Forests. 2018. https://doi.org/10.3390/f9070414.

65. Sanchez-Salguero R, Julio Camarero J, Rozas V, Genova M, Olano JM, Arzac A, et al. Resist, recover or both? Growth plasticity in response to drought is geographically structured and linked to intraspecific variability in Pinus pinaster. J Biogeogr. 2018;45:112639. https://doi.org/10.1111/jbi.13202.

66. Ponton S, Bornot Y, Bréda N. Soil fertilization transiently increases radial growth in sessile oaks but does not change their resilience to severe soil water deficit. For Ecol Manag. 2019;432:923-31. https://doi.org/10.1016/j.foreco.2018.10.027.

67. Rais A, van de Kuilen J-WG, Pretzsch H. Growth reaction patterns of tree height, diameter, and volume of douglas-fir (Pseudotsuga menziesii [Mirb.] Franco) under acute drought stress in Southern Germany. Eur J For Res. 2014;133:1043-56. https://doi.org/10. 1007/s10342-014-0821-7.

68. Pretzsch H, Schutze G, Uhl E. Resistance of European tree species to drought stress in mixed versus pure forests: evidence of stress release by inter-specific facilitation. Plant Biol. 2013;15:483-95. https://doi.org/10.1111/j.1438-8677.2012.00670.x.

69. Sohn JA, Gebhardt T, Ammer C, Bauhus J, Häberle K-H, Matyssek $\mathrm{R}$, et al. Mitigation of drought by thinning: short-term and longterm effects on growth and physiological performance of Norway spruce (Picea abies). For Ecol Manag. 2013;308:188-97. https:// doi.org/10.1016/j.foreco.2013.07.048.

70. Skiadaresis G, Schwarz JA, Bauhus J. Groundwater extraction in floodplain forests reduces radial growth and increases summer drought sensitivity of pedunculate oak trees (Quercus robur L.). Front For Glob Change. 2019;2:267. https://doi.org/10.3389/ffgc.2019.00005.

71.• Thurm EA, Uhl E, Pretzsch H. Mixture reduces climate sensitivity of douglas-fir stem growth. For Ecol Manag. 2016;376:205-20. https://doi.org/10.1016/j.foreco.2016.06.020 This study introduces two alternative indices for assessing growth response of trees to drought; they complement the commonly used indices suggested by [13].
72. Pimm SL. The complexity and stability of ecosystems. Nature. 1984;307:321-6.

73. Anderegg WRL, Schwalm C, Biondi F, Camarero JJ, Koch G, Litvak M, et al. Pervasive drought legacies in forest ecosystems and their implications for carbon cycle models. Science. 2015;349:528-32. https://doi.org/10.1126/science.aab1833.

74. Martínez-Vilalta J, López BC, Loepfe L, Lloret F. Stand- and treelevel determinants of the drought response of Scots pine radial growth. Oecologia. 2012;168:877-88. https://doi.org/10.1007/ s00442-011-2132-8.

75. Trouve R, Bontemps J-D, Collet C, Seynave I, Lebourgeois F. Radial growth resilience of sessile oak after drought is affected by site water status, stand density, and social status. Trees-Struct Function. 2017;31: 517-29. https://doi.org/10.1007/s00468-016-1479-1.

76. Kunz J, Loeffler G, Bauhus J. Minor European broadleaved tree species are more drought-tolerant than Fagus sylvatica but not more tolerant than Quercus petraea. For Ecol Manag. 2018;414:15-27. https://doi.org/10.1016/j.foreco.2018.02.016.

77.• Stuart-Haentjens E, de Boeck HJ, Lemoine NP, Mand P, KroelDulay G, Schmidt IK, et al. Mean annual precipitation predicts primary production resistance and resilience to extreme drought. Sci Total Environ. 2018;636:360-6. https://doi.org/10.1016/j. scitotenv.2018.04.290 This is a global meta-analysis in which the existence of the hypothesized trade-off between resistance and recovery could not be confirmed.

78. Sohn JA, Kohler M, Gessler A, Bauhus J. Interactions of thinning and stem height on the drought response of radial stem growth and isotopic composition of Norway spruce (Picea abies). Tree Physiol. 2012;32:1199-213. https://doi.org/10.1093/treephys/tps077.

79. Navarro-Cerrillo RM, Rodriguez-Vallejo C, Silveiro E, Hortal A, Palacios-Rodriguez G, Duque-Lazo J, et al. Cumulative drought stress leads to a loss of growth resilience and explains higher mortality in planted than in naturally regenerated Pinus pinaster stands. Forests. 2018;9. https://doi.org/10.3390/f9060358.

80. de Grandpré L, Kneeshaw DD, Perigon S, Boucher D, Marchand M, Pureswaran D, et al. Adverse climatic periods precede and amplify defoliator-induced tree mortality in eastern boreal North America. J Ecol. 2019;107:452-67. https://doi.org/10.1111/1365-2745.13012.

81. Diaconu D, Kahle H-P, Spiecker H. Thinning increases drought tolerance of European beech: a case study on two forested slopes on opposite sides of a valley. Eur J For Res. 2017;136:319-28. https://doi.org/10.1007/s10342-017-1033-8.

82. Kunz J, Raeder A, Bauhus J. Effects of drought and rewetting on growth and gas exchange of minor European broadleaved tree species. Forests. 2016. https://doi.org/10.3390/f7100239 This study provides an example for a comparative ranking procedure of drought tolerance among several tree species.

83. Vitali V, Bauhus J. Weißtanne und Douglasie als Ersatz für die Fichte. AFZ- Der Wald. 2019;13:23-26.

84. Buras A, Rammig A, Zang CS. Quantifying impacts of the drought 2018 on European ecosystems in comparison to. Biogeosci Discuss. 2003;2019:1-23. https://doi.org/10.5194/bg-2019-286.

85. Schnabel F, Schwarz JA, Dănescu A, Fichtner A, Nock CA, Bauhus J, et al. Drivers of productivity and its temporal stability in a tropical tree diversity experiment. Glob Chang Biol. 2019;25: 4257-72. https://doi.org/10.1111/gcb.14792.

86. del Río M, Pretzsch H, Ruíz-Peinado R, Ampoorter E, Annighöfer $\mathrm{P}$, Barbeito I, et al. Species interactions increase the temporal stability of community productivity in Pinus sylvestris-Fagus sylvatica mixtures across Europe. J Ecol. 2017;105:1032-43. https://doi.org/10.1111/1365-2745.12727.

Publisher's Note Springer Nature remains neutral with regard to jurisdictional claims in published maps and institutional affiliations. 